\title{
Unsaturated flow in hydrating porous media with application to cemented mine backfill
}

\begin{tabular}{|r|l|}
\hline Journal: & Canadian Geotechnical Journal \\
\hline Manuscript ID & cgj-2015-0314.R3 \\
\hline Manuscript Type: & Article \\
\hline Date Submitted by the Author: & 27-Sep-2016 \\
\hline Complete List of Authors: & $\begin{array}{l}\text { Witteman, Mandy; Thurber Engineering Ltd., } \\
\text { Simms, Paul; Carleton University, }\end{array}$ \\
\hline Keyword: & unsaturated, tailings, backfill, hydration, consolidation \\
\hline
\end{tabular}




\title{
Unsaturated flow in hydrating porous media with application to cemented mine backfill
}

Witteman, M.L. and Simms, P.H.

Department of Civil and Environmental Engineering

Carleton University, Ottawa, Canada ${ }^{1}$

\begin{abstract}
Unsaturated flow in hydrating porous media is pertinent to several engineering applications, including underground and surface use of cemented tailings. Proper description and modelling of flow in complicated by both changes in material properties due to hydration, as well as by the generation of suction by the net consumption of water volume by hydration, variously termed chemical shrinkage or self-desiccation. Not only is it necessary to define changes in hydraulic properties with time, but the SWCC is not unique in time in addition to being path (drying versus wetting) dependent. To address this problem, a theory for modelling unsaturated flow in hydrating materials is introduced. The theory deconstructs the soil-water characteristic curve into a pore-size distribution, which changes with time as hydration occurs, and the water content, which is a variable that must be tracked with space and time. Matric suction depends on the time dependent SWCC and the water content variable. The theory is applied to a multilayer deposition experiment performed in a column, and shows reasonable results.
\end{abstract}

Keywords: Cemented soils, backfill, unsaturated soils, mining, tailings

${ }^{1}$ Corresponding author: paul.simms@ carleton.ca 


\section{INTRODUCTION}

The motivation for studying unsaturated flow in hydrating porous media comes from analysis of Cemented Paste Backfill (CPB) systems, a mainstream practice in today's hard rock mining industry (e.g. Mkadmi et al. 2014; Belem and Benzaazoua 2008; Landriault 2001). CPB is created by mixing tailings with cement and other binders and is subsequently deposited into mined out voids or "stopes". Filling stopes with CPB increases the overall stability of underground mine works, and hence facilitates removal of additional ore. The diversion of tailings to underground has the additional benefit of reducing surface disposal of tailings. The tailings, which are the silt to sand size residual from the grinding of ore, are dewatered to the extent that the CPB exhibits a yield stress and hence can be pumped as a "paste" in the laminar range with no or little settling out of particles during transport. Hence, the resulting CPB deposit is relatively homogeneous in terms of grain size and gains strength faster than tailings-cement backfill with higher water contents such as hydraulic fill, which uses only the coarse fraction of the tailings.

$\mathrm{CPB}$ is often deposited in stopes over 50 meters high. At the bottom of an open stope, a structural barricade is placed to contain the fill. Many backfilling operations implement a vertical rise rate in excess of $10 \mathrm{~m}$ per day (le Roux 2004). Rate of rise is restricted by the rate of pore-water pressure dissipation and associated consolidation and strength gain, which increases as a function of consolidation and hydration time. Dissipation of pore-water pressure and development of strength in the backfill must occur quickly enough so as not to rupture the barricade, and also to allow for timely removal of adjacent pillars (Belem and Benzaazoua 2008; Belem et al. 2001; Li et al. 2005; and Grabinsky and Bawden 2007). As CPB uses total tailings (coarse and fine fractions), which have a relatively low saturated hydraulic conductivity (less 
than $1 \times 10^{-6} \mathrm{~m} / \mathrm{s}$ ), consolidation occurs relatively slowly. Hence, very little water, if any, is visually observed to drain out the bottom of CPB stopes (le Roux 2004; le Roux et al. 2005). However, consolidation in CPB may be accelerated by the phenomenon of self-desiccation.

Self-desiccation is well-known to occur during cement hydration in concrete (Hua et al. 1995; Acker 2004), where the total volume of hydration products is less than the volume of original reactants (binder, water). Accompanying this process is an increase in stiffness: together these phenomena can dissipate positive pore-water pressures (PWP) or even induce negative porewater pressures and /or desaturation if the air-entry value (AEV) of the CPB is exceeded. In hydrating $\mathrm{CPB}$, significant dissipation of PWP can occur even though the quantity of water removed by hydration is relatively small. This holds true if the PWP is positive, or is negative but lies above the air-entry value (Simms and Grabinsky 2009). Evidence of self-desiccation has been observed in CPB; for example, Simms and Grabinsky (2009) and Witteman and Simms (2010) observed significant generation of matric suctions (for example, over $100 \mathrm{kPa}$ by the $6^{\text {th }}$ day of curing) in sealed laboratory specimens containing 5\% binder material. Substantial research has been done on incorporating self-desiccation into pore-water pressure dissipation in large strain consolidation formulations: Helinski et al. (2007, 2010, 2011) conducted laboratory experiments on saturated CPB samples and found that self-desiccation significantly reduced excess PWP. Helinski and co-workers developed analysis of CPB stopes using a large-strain consolidation framework. Wood and Doherty (2014) developed analytical solutions for consolidation incorporating self-desiccation.

While unsaturated conditions would be less common than saturated conditions, certainly some stopes do become unsaturated (Thompson et al. 2010; Thompson et al. 2011). Indeed, research is ongoing at different groups to profit from drainage and unsaturated conditions in order to reduce 
binder contents and associated costs. Unsaturated conditions would also arise during the selective use of cemented tailings to enhance the stability of surface tailing deposits (Deschamps et al. 2008). Witteman and Simms (2010, 2011) and Abdul-Husain and Fall (2011) report measurements of the soil-water characteristic curve (SWCC) of hydrated cemented tailings.

\section{FORMULATION OF UNSATURATED FLOW THEORY FOR A HYDRATING MATERIAL}

A modified one-dimensional unsaturated flow model to estimate the distribution of porepressures can be stated as:

$$
m_{w} \frac{\partial \psi}{\partial t}=\frac{\partial}{\partial z}\left[k(\psi) \frac{\partial h}{\partial z}\right]-S_{k}
$$

where $m_{w}$ is the coefficient of water storage (or release) through volume compressibility and desaturation, $k(\psi)$ is the hydraulic conductivity, which is a product of the saturated hydraulic conductivity and the relative hydraulic conductivity (a function of matric suction). The value of $m_{w}$ is defined by the slope of the SWCC in a plot of volumetric water content versus matric suction. Below the AEV, the value of $m_{w}$ may approach the compressibility of the material as measured in an oedometer, however, even the small degree of desaturation that occurs below the AEV is sufficient to result in a value substantially larger than the compressibility. The saturated hydraulic conductivity may vary due to volume change through consolidation, and also by poreobstruction due to hydration. $S_{\mathrm{k}}$ is the sink term to account for the removal of water, caused by an inequality between the loss of water volume and the acquired volume of hydration products. Equation 1 is simply the Richard's equation with the addition of the sink term. 
In this work the application of Equation 1 is tested under low total stress conditions $(<20 \mathrm{kPa})$, where the change in pore-space characteristics due to compression is expected to be small. However, there is nothing that prevents Equation 1 from being adopted into a generalized large strain formulation, such as an incremental small-strain / piecewise linear formulation (e.g. Fox and Berles 1997).

Equation 1 requires measurement of the material properties of $\mathrm{CPB}$. The use of Equation 1 is complicated by the evolution in the material properties due to binder hydration. Presently, there are no published techniques to measure the complete evolving water-retention characteristics of hydrating materials, largely because most techniques rely upon achieving a steady-state condition. Goudbot et al. (2009) and Abdul-Hussain and Fall (2011) attempted to track the AEV using axis-translation and total suction measurements, respectively. Witteman (2013) and Witteman and Simms (2011) measured the upper and lower bounds of the SWCC, before and after hydration, and used this to generate bounding solutions for certain scenarios. A more general approach is explored in this paper.

The basic concept applied to solve Equation 1 is to separate the SWCC into a cumulative poresize distribution, which evolves with hydration, and to track water content at a point in soil (or tailings) over time. Classically, the SWCC is assumed to represent a constant pore-size distribution (Fredlund and Rahardjo 1993), and this is reasonable for coarse-grained soils. However, Simms and Yanful (2005), and others since, have shown that the SWCC of fine grained soils such as clays, whether drying from a slurry, or from a compacted state, is not representative of a cumulative pore-size distribution, and indeed the pore size distribution (PSD) changes considerably with drying, both in terms of total volume and shape. The PSD also changes with total stress. The change in the PSD is not necessarily problematic for modelling 
such soils, as long as the limitations of assuming a constant PSD, such as the limitations of statistical methods to predict unsaturated hydraulic conductivity (as reviewed by Leong and Rahardjo 1998) are recognized. Though the PSD changes with suction, it does not change independently of suction with time. In the case of hydrating materials such as CPB, not only does the PSD evolve with drying, but it also changes with time (as pores fill with hydration products) irrespective of the degree of drying and wetting.

Therefore, the SWCC must be treated as a time varying property to properly analyze drying of a hydrating material. Henceforward in this paper, the SWCC is taken to be a relationship between suction and water content (or degree of saturation) that changes with time, a relationship that is a physical manifestation of a PSD at a given time. The proposed approach is illustrated in Figure 1, which shows two hypothetical SWCCs for adjacent time steps. The figures begs the question as to how a change in water content with a change in suction (or vice versa) can be calculated in a given time step over which the SWCC is changing. If suction is assumed to be constant between the end of one time step and the start of the next, this can lead to an erroneous change in mass calculated by the solution, as indicated in Figure 1 by the constant suction path. Conserving mass of water from the end of one time step to the beginning of the next time step, however, will avoid this problem. The latter approach is physically more correct, as the water content should in fact not change between the end of the last time step and the beginning of the first, and hydration will reduce average pore-size, which will increase suction for a given constant mass of water,

A relatively simple numerical method is adopted: one dimensional finite difference using a central finite difference in space and forward finite difference in time to solve Equation 1, keeping the units in terms of volumetric water content (VWC): 


$$
\Delta V W C=\Delta t\left(\frac{k}{\Delta z^{2}}\left[H_{1}+H_{3}-2 H_{2}\right]-S_{k}\right)
$$

Where $k$ is the hydraulic conductivity, which will vary with hydration as well as with degree of saturation, $\Delta t$ is the time step, and $\Delta z$ is the node spacing. $H_{2}, H_{1}$, and $H_{3}$, are the total heads at the central and two adjacent nodes, and $S_{k}$ is the sink term of units of change in VWC with time.

To obtain heads for the next time step, the change in matric suction (or positive PWP) for a change in water content must be calculated. This change is suction is found by dividing the change in VWC by the coefficient of water storage $\left(\mathrm{m}_{\mathrm{w}}\right)$, which at any one time is the slope of the SWCC at a particular matric suction. Elevation head is constant.

The formulation of the sink term and the water storage term $\left(m_{w}\right)$ will be discussed in the experimental section, which describes measurement of the SWCC for pre and post hydration tailings, measurement of the evolving PSD using MIP to estimate the change in the SWCC with time, and self-desiccation tests to determine $m_{w}$ and the sink term. The modelling approach is tested against data from a multilayer deposition experiment of layers of CPB using the same tailings.

\section{MATERIALS AND METHODS}

\section{Materials}

The tailings are from the Williams / Hemlo Gold Mine in Northern Ontario. These tailings are predominantly silty-clays (CL-ML) and non-plastic (LL-24\%, PL-23\%, PI-1\%). The particle size-distribution (PSD) curve is presented in Figure 2, and is typical of gold tailings (Bussiere 2007). Detailed mineralogy and solid and pore-water composition are given in Thompson et al. (2011) and Witteman (2013). 
With the exception of some self-desiccation tests, CPB was created by mixing $3 \%$ dry mass of binder to dry mass of tailings with equal parts of fly ash (FA) and Ordinary Portland cement (OPC). The water content of all tailings samples was $39 \%$ before the addition of binder. Yield stress determined from slump tests (Pashias et al. 1996) was about $100 \mathrm{~Pa}$, sufficient for pumping in the laminar range without particle segregation.

\section{Tailings and post-curing CPB soil-water characteristic curves}

The soil-water characteristic curve for raw tailings, and for tailings with $3 \%$ binder after 28 days of hydration, were measured using axis-translation for relatively low suctions, and a chilled mirror hygrometer for higher suctions. The axis-translation tests, undertaken taken using the Fredlund cell device sold by GCTS and using a 5 bar capacity ceramic disc, follow standard methods; except that volume change is estimated at each stage by removing the top of the cell after equilibration and taking vertical displacement measurements using a non-contact ultrasonic displacement sensor. Tailings did separate from the side of the axis-translation test during the SWCC test. The side separation was estimated using calipers.

To determine a "post-curing" SWCC, the sample was poured into the cell, sealed from any moisture loss, and cured at standard atmospheric pressure (i.e. without applied air pressure). On day 29, the sample was re-saturated, and the axis-translation test was initiated. During this time, weight and volume changes were recorded and measured during the 28 days of curing. For suctions in excess of $500 \mathrm{kPa}$, the specimen was removed from the axis-translation test cell, and allowed to dry. Small samples were periodically cut from the larger sample. Each of these samples was then inserted into a WP4 - DewPoint Hygrometer from Decagon Devices to 
determine total suction. The same sample was then placed in an oven to determine water content. The SWCC of the un-amended tailings was determined using the same procedure, on samples that were prepared at $\mathrm{w}=39 \%$, but then allowed to complete settling (to about $30 \%$ ) before the initiation of the first stage of the axis-translation test.

\section{Self-Desiccation tests}

Self-desiccation tests are designed to monitor hydration and matric suction development on samples that are free to settle and unloaded. CPB specimens for a range of binder dose $(0,3,5$, and 7\%) were prepared and poured into $10 \mathrm{~cm}$ diameter and $25 \mathrm{~cm}$ high PVC containers. Porewater pressure transducers / tensiometers (Model T5 from UMS) were inserted from the top into the fresh paste material. The tops of the PVC containers were covered with plastic wrap to prevent water loss from evaporation. Matric suction measurements were recorded every 5 minutes for the first 48 hours and at every 10 minutes thereafter for 28 days. Some release of bleed water typically occurred within the first couple of hours of setting for all three CPB specimens, while the control ( $0 \%$ binder) specimen settled for over 24 hours. Water that pooled onto the surface from settling in the CPB specimens was removed with a syringe after 4 hours.

Replicate sealed samples were prepared in order to sample for gravimetric water content and change in total mass of solids after oven drying over time to track hydration by a change in the water-to-solids ratio. These samples were weighed to ensure no loss of water by evaporation. The change in water content was then used to calculate the sink term.

\section{Mercury intrusion porosimetry (MIP) tests}


Specimens were obtained from tailings with no binder after settling, and CPB containing $3 \%$ binder at different hydration times. These samples were cut down to a size of approximately 1 $\mathrm{cm}^{3}$, and subsequently freeze-dried using liquid nitrogen, employing pentane as an intermediate fluid to accelerate the rate of freezing (Delage et al. 1982; Simms 2003). Samples were subsequently dehydrated by sublimation in a cooled desiccator, under vacuum for 1 hour.

Specimens were prepared for each day during hydration (Day 1 through Day 28). Dehydrated specimens were tested using a porosimeter in University of Toronto's concrete science laboratory.

\section{Multi-layer Column test}

A column test was conducted in a 0.30 by 0.30 m square Plexiglas column. The column had a drainage port at the bottom with a $5 \mathrm{~cm}$ drainage layer, comprised of gravel under a geotextile filter. Water flowing out of the drainage port was collected in a beaker resting on a scale. A cover was placed on top of the column to minimize evaporation. A number of ports were fitted on the column for five (5) tensiometers and eight (8) EC sensors (10HS model from Decagon Devices) to measure volumetric water content (VWC). The tensiometers were the same model used in the self-desiccation tests. Pictures of the test setup, details of sensor calibration, and other details can be found in Witteman (2013).

The CPB (3\% binder) was placed in four layers. The first layer was left to cure for twenty days before placing the next layer; each subsequent layer was placed after about 30 days. The first layer was $0.15 \mathrm{~m}$ deep; subsequent layers were $0.30 \mathrm{~m}$ deep. Tensiometers and VWC sensors were located roughly in the middle of each layer. 


\section{EXPERIMENTAL RESULTS}

\section{Soil-Water Characteristic Curves}

The SWCC of un-amended tailings and the SWCC of CPB prepared with $3 \%$ binder are presented in Figures 3 and 4, respectively in terms of water contents, and degree of saturation. The corresponding shrinkage curves are presented in Figure 5. The degree of saturation curves for the post-curing samples have more or less the same shape as the gravimetric water content curves, as very little volume changes occurred during these tests. The degree of saturation curves looks quite different for the un-amended tailings, as a significant amount of volume change occurs at low suctions. The AEV of the tailings with no binder is $50 \mathrm{kPa}$, and the AEV of the post-hydration specimen is $140 \mathrm{kPa}$.

\section{Self-desiccation tests}

Results of the self-desiccation tests for tailings 0,3,5 and $7 \%$ binder are presented in Figure 6. As expected, a higher binder content increases the rate of suction generation.

All of the data exhibit at least three distinct stages of suction development: a period of little or no suction development, followed by a period of linear increase in suction, followed by a trend of decreasing suction increase. The first stage is due to both induction of the hydration process ( a delay in the onset of hydration observed in all cement) and the release of water by settling, The second stage is due to the simultaneous processes of water consumption and increase in stiffness due to hydration. The last stage is due the steepening of the SWCC as the AEV is approached and passed, resulting in a smaller rate of suction of increase for a given sink rate. 
To temporarily extend the measurement range over $100 \mathrm{kPa}$, the T5 tensiometers are conditioned using cycles of positive and negative pore-water pressure to eliminate cavitation nuclei, as suggested by Guan and Fredlund (1997). The maximum theoretical suction measurable by the tensiometers is the AEV of their ceramic tips, which is $300 \mathrm{kPa}$. When the T5 tensiometers cavitate, the drop in suction is abrupt.

Figure 7 shows the change in gravimetric water content during the self-desiccation test for $3 \%$ binder. This data was obtained from replicated sealed samples, where the overall change in mass was negligible; therefore, the change in water content represented the change in proportion of the mass of water to the mass of solids. As the mass of solids is equal to the total mass / divided by the water content plus unity, the increase in solids due to hydration can also calculated by measuring $w$. As remarked on earlier in the paper, some settling and corresponding water release does occur to the surface of the CPB, and this is removed after 4 hours by using a syringe. However, the release of water from settling is part of the change in water content measured in Figure 7, at least for the first 24 hours.

The water content data in Figure 7 can then be used to construct a sink term, calculating the difference between the new volume of solids and the volume of water lost, assuming the density in non-evaporable water incorporated into hydration products to be $1.39 \mathrm{~g} / \mathrm{cm}^{3}$ (Bouwers 2004; Powers and Brownyard 1947). It is assumed that the water removed by oven-drying constitutes both capillary water and gel water. Gel water refers to water absorbed into micropores within the cement but not physically bound into the hydration products. The change in density of gel water postulated by some workers (up to $1.11 \mathrm{~g} / \mathrm{cm}^{3}$, per Bouwers 2004) is ignored. Gel water is about $40 \%$ of the water absorbed into the cement (Bouwers 2004), so an error of less than $5 \%$ 
can be attributed to this assumption. Following these assumptions a best fit power function is derived:

$$
S_{K}=0.028 \mathrm{t}^{-1.137}
$$

where $t$ is in days. The equation is also shown in Figure 7.

Having defined the sink term, it is now possible to extrapolate the expression for the water storage coefficient from the self-desiccation test. If it can be assumed that in the self-desiccation test that water is removed by hydration only, the contribution of drainage can be ignored to reduce Equation 1 to Equation 4, rearranging to solve for $m_{w}$ :

$$
m_{v}=-S_{K} /\left(\frac{\partial \psi}{\partial t}\right)
$$

where, $(\partial \psi / \partial t)$ is the change in matric suction as a function of hydration time, [kPa/day]; and, $-S_{K}$ is the rate of water removal, [1/day].

As the sink term is defined by Equation 3, Equation 4 can then be used to extract $m_{w}$ as function of time. The resulting data is shown in Figure 8. The results appear to be reasonable, as the coefficient of water storage determined from the self-desiccation test comes close to the value of the $\mathrm{m}_{\mathrm{w}}$ of the post-hydration sample determined from the post-hydration SWCC. The initial $\mathrm{m}_{\mathrm{w}}$ value determined from the self-desiccation is above the value determined from the SWCC of the raw tailings. This is expected, since the value for the raw tailings was obtained from a sample 
that had settles naturally to $\mathrm{w}=30 \%$. As noted by many in the literature (for example Abdelaal 2011; Fall et al. 2009), the stiffness of CPB substantially increases with hydration time, and therefore the water storage term substantially decreases,

The best fit line in Figure 8, which defines the water storage coefficient before the AEV, is give by::

$$
0.004 t^{-1.137}
$$

with units of $1 / \mathrm{kPa}$, and where $\mathrm{t}$ is in days.

\section{Evolution of pore-size distribution}

The differential and cumulative PSD curves for the $3 \%$ binder CPB for different hydration times are presented in Figure 9. The raw tailings sample had a smaller average pore-radius $(\sim 0.11 \mu \mathrm{m})$ than the $3 \%$ binder specimens cured for 2 and 3 days $(\sim 0.15 \mu \mathrm{m})$, which is because the development of stiffness through hydration impedes settlement or self-weight consolidation. Similar findings have been reported (Deschamps et al. 2008), where the addition of binder decreased settlement. Both the peak pore diameter of the larger pore mode and the threshold diameter (defined by the diameter below which the frequency of pores continually increases until the peak pore is reached) decreased with curing time. The specific surface and void ratio increased with curing time. 
The PSD distribution can be used to estimate of the how the SWCC changes with time. If issues such as pore accessibility are ignored (see Simms and Yanful 2005), the capillary tube model can be used to estimate the SWCC from a PSD by transforming pore diameter to suction. The evolving estimated SWCC along with the two measured curves for raw tailings and for the CPB after 28 days of hydration are shown in Figure 10. The SWCCs generated from the MIP data lie between the SWCC for tailings without binder and the SWCC after 28 days of curing, with progressively increasing AEVs and decreasing water storage.

The PSD distribution data can be used to estimate how the AEV changes with time, if it is assumed that the threshold diameter corresponds to the AEV (Figure 11). Best fitting the pore size distribution data gives the following relationship between the AEV and time:

$$
A E V(k P a)=61.8 t^{0.23}
$$

where $\mathrm{t}$ is time in days. The AEV defined by this equation gives a value of $127 \mathrm{kPa}$ at 28 days, close to the AEV measured for the cured $\mathrm{CPB}$ sample (120 kPa from Figure 4). Equation 6 is somewhat different to the one other approximation of $\mathrm{AEV}$ found in the literature for CPB reported by Abdul-Hussain and Fall (2011), who reported AEV as a positive power function of hydration with an exponent greater than 1, hydration being defined using ratios of UCS strength. Abdul-Hussain and Fall (2011) defined their SWCC using measurement of total suction using a dewpoint hygrometer and salt solutions. 
Matric suction and water content profiles from the column test

Matric suction and volumetric water content profiles from the column test are presented in Figures 12 and 13, respectively. There are visible trends of decreasing water content, but the magnitudes of the changes are relatively small (Figure 13). This is not surprising, due to the relatively high AEV of the fully hydrated tailings $(140 \mathrm{kPa})$, and the fact that suction for all layers reaches a maximum matric suction of $80 \mathrm{kPa}$. At any one time, the difference in matric suctions between layers were relatively small, tending toward the difference in elevation between the sensors. The differences in suction levels between fresh and old layers dissipated within 5 minutes after deposition, 5 minutes being the data-logging interval.

The effect of increasing volume of older desiccated tailings under the fresh tailings was a decrease in the overall rate of suction generation. This is shown in Figure 14 where the suction values are overlaid, with time $=0$ is the deposition time of each layer.

MODEL IMPLEMENTATION AND NUMERICAL SIMULATION OF THE SELF-DESICCATION AND

COLUMN TESTS

Material parameters 
The transient SWCC is modelled by tracking the evolving $m_{w}$ using a best fit power function to Figure 8 as defined in Equation 5. The AEV is also tracked with time, using the power function based on the MIP data in Figure 11 and as defined in Equation 6. The sink term is defined by the power function determined from the change in measured gravimetric water content in the selfdesiccation test and replicates, and is defined in Equation 3. Though saturated hydraulic is known to vary by 1.5 orders of magnitude from the raw to the hydrated Williams tailings (LeRoux 2004), the value in the model was assumed to be constant at the fully hydrated value of $2 \times 10^{-8} \mathrm{~m} / \mathrm{s}$. A Brooks and Corey (1964) formulation was employed to estimate the unsaturated hydraulic conductivity.

Both $m_{\mathrm{w}}$ and the AEV were capped at their lowest and highest values respectively to the values measured after 28 days. The initial values of the sink term and $m_{w}$ were also capped: the choice of these values is discussed in the initial conditions section.

To reduce computational complexity, the water storage term for when the AEV exceeded was taken to be constant and to be the value from slope of the post-hydration SWCC: $0.00124 / \mathrm{kPa}$.

Tailings older than 28 days were assumed to retain the properties measured at 28 days. As such the $m_{w}$ value for older tailings before the AEV was kept constant at $0.0002 / \mathrm{kPa}$. The AEV for all CPB was assumed not to exceed $140 \mathrm{kPa}$.

\section{Initial conditions, boundary conditions, time step, and discretization.}

The initial conditions for the fresh tailings were assumed to be constant head, with initial PWP varying linearly from zero at the surface to the height of the layer times bulk unit weight at the bottom. An initial VWC of 0.51 was used in the fresh layer, corresponding to the measured 
initial VWC immediately after CPB preparation, In the multi-layer simulations, a constant matric suction and water content were assumed for the older tailings, corresponding to the suction and water content measured just before deposition of fresh tailings.

Top and bottom boundary conditions are set to be no flow, except for the first layer where drainage was the high compared to the total mass of tailings (Drainage was equivalent to a $0.4 \%$ change in gravimetric water content). For the first layer, both a no flow boundary and a prescribed flow boundary were implemented.

A node spacing of $0.01 \mathrm{~m}$ and a time step of $1 \times 10^{-6}$ days were used. In the multi-layer simulations, smaller time steps were used at the beginning (first 0.1 days) to avoid instability associated with high gradients of head at the interface between new and old tailings.

The model is implemented in visual basic with output to excel. A version of the model is attached with this submission that simulates the self-desiccation but not drainage $(\mathrm{k}=0)$, which allows for relatively quick and stable solutions, and so can be assessed by the reviewers /readers should they so wish. This version is setup in excel with the automatic calculation disable. Users must press the "calculate now" button for the model to run.

A conceptual sketch of the two modelled scenarios is shown in Figure 15.

\section{Results -Simulated self-desiccation tests}

The self-desiccation test for $3 \%$ binder was simulated by setting hydraulic conductivity equal to zero, hence suction is generated only due to the removal of water by hydration and change in 
stiffness and AEV. This may be seen as a check on the use of the power functions to describe both the change in $\mathrm{m}_{\mathrm{w}}$ and the sink term.

The results are shown in Figure 16. As shown, the results are sensitive to the maximum instantaneous sink rate, which is required to limit the power function. By contrast, the results are visually indistinguishable when the cap on the initial $\mathrm{m}_{\mathrm{w}}$ value is varied over a plausible range $(0.5$ to 0.005$)$ of values.

The variance in the two measured tests is likely due to the fact that water generated by settling was removed using a syringe in one but not in the other. Therefore, the cap on the sink term is serving as a factor to account for the differences in water availability. When the cap is a low value, this allows for more water to be available to the tailings later in the simulation, hence lower suctions values. In essence, the integration of the sink term early in the simulation is corrected to account for variability in the water available from settling.

For the simulations with the higher sink rate caps ( 0.1 and 0.01 per day), the AEV begins to affect the results at about 18 days. Suction development becomes limited by the value of the AEV (which is changing with time). Past the AEV the amount of water released per change in suction is high, therefore the effect of hydration on suction development is much reduced. Therefore, the transient AEV is more or less a cap on suction development. If suction does not approach the AEV, suction will develop linearly with time, as the sink and $\mathrm{m}_{\mathrm{w}}$ terms are defined as power functions of time with the same exponent, at least after the sink term drops below its cap value and until the minimum value of $m_{w}$ is reached. In the simulations in Figure 15, the minimum value of $\mathrm{m}_{\mathrm{w}}$ is reached after 15 days. 


\section{Results - Simulation of the column test}

The simulations of matric suction in the column test are presented in Figure 17. The model was run using the sink cap value of 0.1 for all four layers. The agreement between the simulations and measured results are reasonable. The results for Layer 1 for the different boundary conditions (no flux and proscribed flux) are visually indistinguishable. This is probably due to i) the relatively small amount of drainage, and ii) excess water not allowed to drain in the no flux simulation is consumed by the sink term, with relatively small differences in suction due to the high compressibility / low stiffness of the material at this point. The differences between layers 3 and 4 are smaller for both the measured and simulated results, showing that matric suction development shows a decreasing dependency on the thickness of underlying tailings as sequential deposition progresses. In effect, the depth of influence of the underlying tailings appears to be finite.

An example of how suction develops in the first few minutes following deposition in the simulations is shown in Figure 18. The numerical values agree with the actual suction measurements, which show complete dissipation of suction by the first measurement point (5 minutes).

\section{DISCUSSION}

\section{Degree and rate of water consumption by hydration}


Probably the most problematic aspect of the modelling is the difficulty in resolving water release due to settling or initial drainage and its influence on the sink term. If we attribute to the mixed binder the full properties of Portland cement (it is actually a mixture of PC and flyash), the expected change in water content due to hydration is in the order of $2 \% \mathrm{GWC}$, using Powers and Brownyards (1947) original measurements on hydration of Portland Cement. But the actual GWC falls from 36 to $30.5 \%$ during the self-desiccation tests. Based on the settling water removed by a syringe at the surface after 4 hours, the water content decreased to $35 \%$, assuming no change in the mass of solids. Possibly there is further settling or drainage past that point that is not easily detected. There would be no further settling or drainage of water once positive matric suctions are recorded in the self-desiccation tests (at 4 days), where the water content is $31.8 \%$. Therefore, the change in water content while suction are positive can be attributed to hydration

\section{Influence of temperature}

In actual deposits of CPB significant temperature increases can occur and in some stopes would be large enough for the temperature to affect pore-water pressure changes (Fall et al. 2009; Thompson et al. 2011). Temperature changes can effect pore-water pressure development by the temperature dependency of viscosity and density of water, as well as by energy availability for reactions that affect hydration. No variation of temperature was detected in the column tests described in this paper, where temperature is one of the parameters measured by the volumetric water content sensors. 


\section{SUMMARY AND CONCLUSION}

A framework for modelling unsaturated flow in hydrating porous media is presented. The AEV of the SWCC can be tracked over time independently of suction development using pore-size data from MIP. Water content is used as the solution variable rather than suction or head, due to artificial generation of mass that would occur with the latter analysis. A sink term is included in the governing equation to represent the change in volume due to increases in the density of bound water. Both the sink term and the time dependent pre-AEV water storage function can be determined from a self-desiccation test, whereby suction and change in water content are tracked in replicate small sealed samples of hydrating material. The change in the AEV with time can be estimated by correlations with the threshold pore diameter from mercury intrusion porosimetry data.

A model based on these principles is constructed and used to model self-desiccation tests as well as a multilayer deposition test on cemented paste backfill. The model shows reasonable agreement with both cases. The most important calibration parameter is a cap on the value of the sink term, at the beginning of hydration. This parameter accounts for uncertainties in both the degree of settling and when hydration actually begins. Untangling these processes is probably the next step in future work.

\section{REFERENCES}

Abdelaal, A.M.G.M.I. 2011. Early Age Mechanical Behavior and Stiffness Development of Cemented Paste Backfill with Sand. Ph.D. Dissertation, Department of Civil Engineering, Univeristy of Toronto. 
Acker, P. 2004. Swelling, shrinking and creep: a mechanical approach to cement hydration. Materials and Strucures / Concret Science and Engineering , 37, 237-243.

Belem, T., and Benzaazoua, M. 2008. Design and application of underground mine paste backfill technology. Geotech Geol Engineering , 26, 147-174.

Belem, T., Benzaazoua, M., and Bussiere, B. 2000. Mechanical behaviour of cemented paste backfill. In Proceedings of the 53rd Annual Conference of the Canadian Geotechanical Society, Montreal 2000, Vol. I, (pp. 373-380).

Belem, T., Bussiere, B., and Benzaazoua, M. 2001. The effect of microstructural evolution on the physical properties of paste backfill. (R. a. A.A. Balkema, Ed.) In Proceedings of Tailing and Mine Waste '01, Fort Collins, Colorodo USA, 16-19 January 2001, pp. 365-374 .

Belem, T., Harvey, A., Simon, R., and Aubertin, M. 2004. Measurement and prediction of internal stresses in an underground opening during its filling with cemented fill. In Proceedings of the 5th Interantional Symposium on Ground Support in Mining and Undergournd Construction, Australian Centre of Geomechanics, Perth, pp. 619-630.

Dechamps, T., Benzaazoa, M., Bussiere, B., Aubertin, M., and Belem, T. 2008. Microstructual geochemical eveolution of paste tailings in surface disposal conditions. Mineral Engineering (21: 341-353).

Delage, P., Tessier, D., and Marcel-Audiguier, M. 1982. Use of the Cryoscan apparatus for observation of freeze-fractured planes of a sensitive Quebec clay in scanning electron microscopy. Canadian Geotechnical Journal, Vol. 19 (1): 111-114.

Fall, M., Adrien, D., Celestin, J.C., Pokharel, M., Toure, M. 2009. Saturated hydraulic conductivity of cemented paste backfill. Minerals Engineering, 22 (2009): 1307-1317.

Fisseha, B., Bryan, R., and Simms, P. 2010. Evaporation, unsaturatd flow, and salt accumulation in multilayer deposits of a gold "paste" tailings. ACSE Journal of Geotechniucal and Geoenvironmental Engineering , 136: 1703-1713.

Grabinsky, M.W., and Bawden, W.F. 2007. In situ measurements of geotechanical design of cemented paste backfill systems. In Proceedings of Minefill 2007, 29 April - 2 May (Paper No. 2456), pp. [CD-ROM].

Grabinsky, M.W., and Simms, P.H. 2006. Self-desiccation of cemented paste backfill and implications for mine design. (S. L. R.J. Jewell, Ed.) Limerick, Ireland: Australian Centre for Geomechanics, Perth.

Helinski, M., Fahey, M., and Fourie, A. 2007b. Numerical Modeling of Cemented Mine Backfill Deposition. Journal of Geotechnical and Geoenvironmental Engineering , 133 (10), 1308-1319. 
Helinski, M., Fahey, M., and Fourie, A. 2010. Coupled two-dimensional finite element modelling of mine backfilling with cemented tailings. Canadian Geotechnical Journal (47(11): 1187-1200).

Helinski, M., Fahey, M., and Fourie, A. 2011. Behavior of cemented paste backfill in two mine stopes: measurements and modelling. Journal of geotechnical and geoenviromental engineering, Vol. 137(2): 171-182.

Helinski, M., Fourie, A., Fahey, M., and Ismail, M. 2007a. Assessment of the self-desiccation process in cemented mine backfill. Canadian Geotechnical Journal, Vol. 44 (2007):1148-1156 .

Helinski, M., Fourie, M., Fahey, M., Ismail, M. 2007. Assessment of the self-desiccation process in cemented mine backfills. Can. Geotech. J. , 44, 1148-1156.

Hilf, J.W. 1956. An investigation of pore-water pressure in compacted cohesive soil. Ph.D. thesis, Technical Memorandum 654. U.S. Department of the Interior Bureau of Reclamation, Denvor, Colorado.

Hua, C., Acker, P., and Ehrlacher, A. 1995. Analyses and models of the autgenous shrinkage of hardening cement paste. Cement and Concrete Research , 25 (7), 1457-1468.

le Roux, K. 2004. In situ properties and liquefaction potential of cemented paste backfill. $\mathrm{PhD}$ thesis, Graduate department of civil engineering, University of Toronto, Canada.

le Roux, K., Bawden, W.F., and Grabinsky, M.F. 2005. Field properties of cemented paste backfill at the Golden Giant mine. Mining Technology: Trans. of the Institute of Mining and Metallurgy, Section A, Vol. 114(2):65-80.

Li, L., Aubertin, M., and Belem, T. 2005. Formulation of a three dimensional analytical solution to evaluate stesses in backfilled vertical narrow openings. Canadian Geotechnical Journal , 42 (6), 1705-1717.

Marinho, F.A.M., Take, W.A., Tarantino, A. 2008. Measurement of matric suction using tensiometric and axis translation techneques. Geotechnical and Geological Engineering, Vol. 26:615-631.

Mkadmi, N., Aubertin, M., Li, L. 2014. Effect of draiange and sequential filling on the behaviour of backfill in mine stopes. Can. Geotech. J. 51: 1-15.

Simms, P., and Grabinsky, M. 2009. Direct measurement of matric suction in triaxial tests on early-age cemented paste backfill. Can. Geotech. J. , 46, 93-101.

Simms, P.H. 2003. A fundamental study of unsaturated flow in compacted clayey soil. Ph.D Disseration, University of Western Ontario, Department of Civil Engineer. 
Thompson, B.D., Grabinsky, M.W., and Bawden, W.F. 2008. Geomechanical design of cemented paste backfill systems. Dept. of Civil Engineering, University of Toronto. University of Toronto.

Thompson, B.D., Grabinsky, M.W., and Bawden, W.F. 2009. Geomechanical design of cemented paste backfill systems. Department of Civil Engineering, University of Toronto. University of Toronto.

Witteman, M.L. 2013. Unsaturated flow in hydrating porous media: application to cemented paste backfill. In M.A.Sc Thesis. Department of Civil and Environmental Engineering, Carleton University, Ottawa ON.

Witteman, M.L., and Simms, P. H. 2010. Hydraulic response in cemented paste during and after hydration. In a. A. Edited by R. Jewell (Ed.), Paste 2010, In Proceedings of the 13th

International Seminar on Paste and Thickened Tailings, 3-6 May 2010 (pp. 199-207). Toronto, Ontario: Australia Centre for Geomechanics, Perth. 


\section{List of Figures}

Figure 1 Possible paths to translate suction or water content with time where hydration is changing the SWCC.

Figure 2 Grain-size distribution of the tailings

Figure 3 SWCC for tailings with no binder

Figure $4 \quad$ SWCC for CPB with $3 \%$ binder: Test started after 28 days of curing and after resaturation

Figure 5 Shrinkage curves for un-amended tailings, and CPB prepared with $3 \%$ binder

Figure 6 Matric suction measured in sealed samples of CPB, free to shrink

Figure $7 \quad$ Gravimetric water contents of replicate sealed samples of Williams tailings containing $3 \%$ binder and derived sink term

Figure 8 Coefficient of water storage below the AEV estimated from self-desiccation tests

Figure 9 Evolution of differential (a) and cumulative (b) pore-size distributions for Williams paste containing 3\% binder during curing

Figure 10 Measured SWCC data compared with SWCC data estimated from cumulative PSD

Figure 11 Estimated change in AEV with time from PSD data

Figure 12 Matric suctions measured in $30 \mathrm{~cm}$ by $30 \mathrm{~cm}$ square column test, sensors at 5, 20, 40,60 , and $80 \mathrm{~cm}$ elevations

Figure 13 Volumetric water content data from column test

Figure 14 Matric suction from the bottom ( $5 \mathrm{~cm}$ elevation) sensor, time is time after deposition of the newest layer

Figure 15 Schematic of modelled scenarios: Self-desiccation test (left) and multilayer column test (right)

Figure 16 Modelling of self-desiccation tests, showing sensitivity to cap on initial sink rate

Figure 17 Measured and modelled matric suctions for the multilayer column test

Figure 18 Dissipation of matric suction in underlying tailings after deposition of second layer 


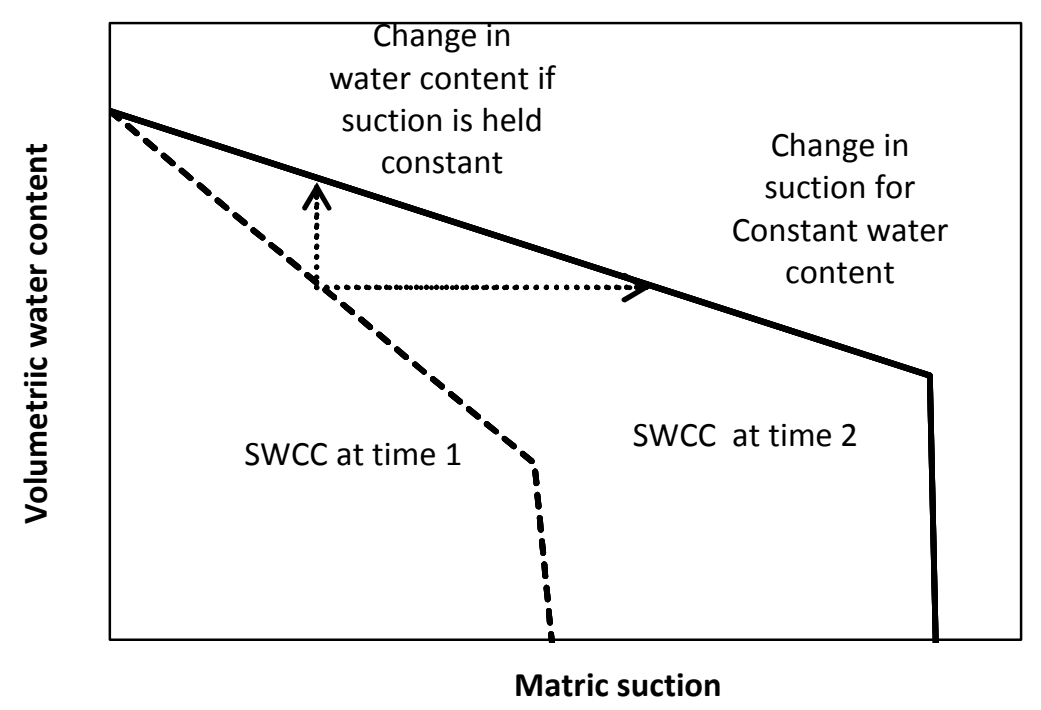

Figure 1. 


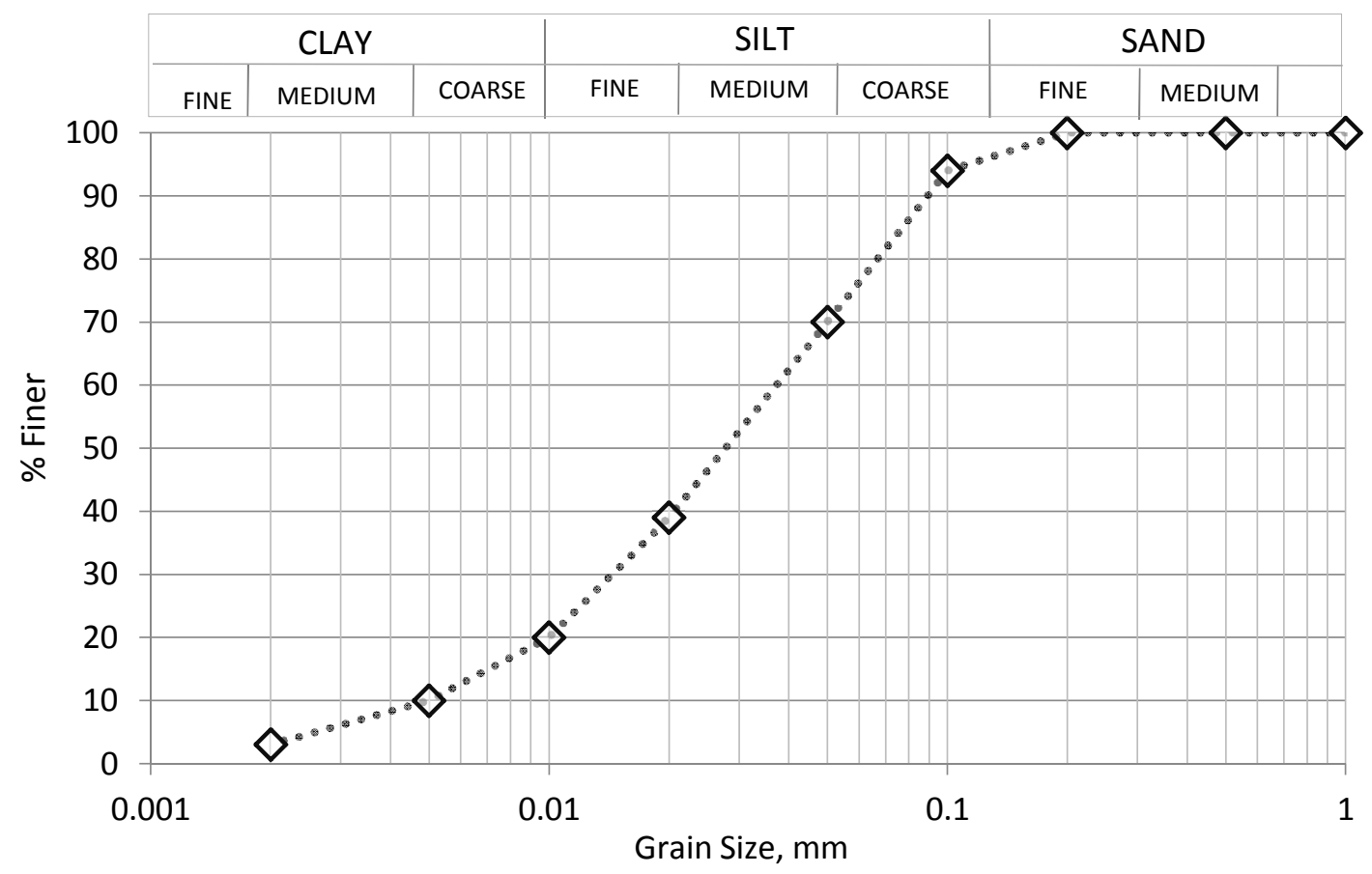

Figure 2. 


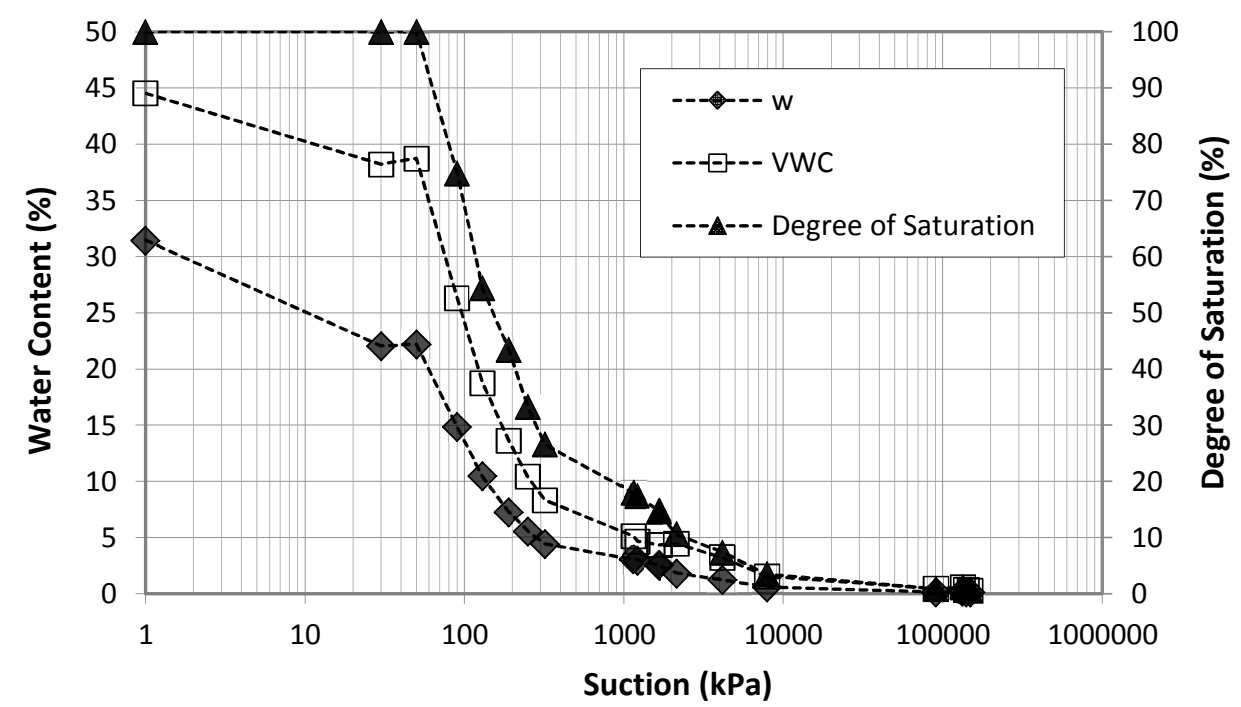

Figure 3. 


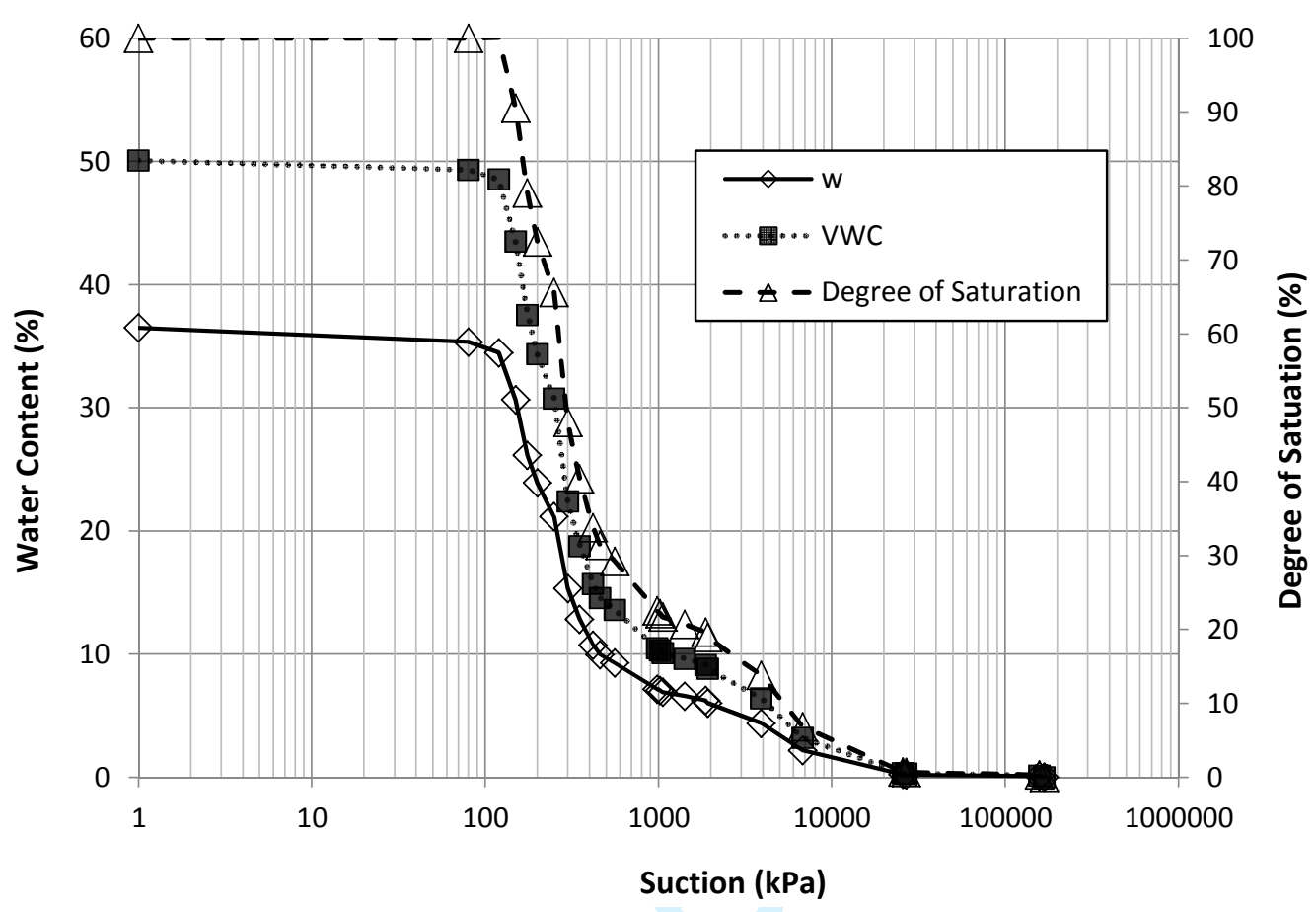

Figure 4. 


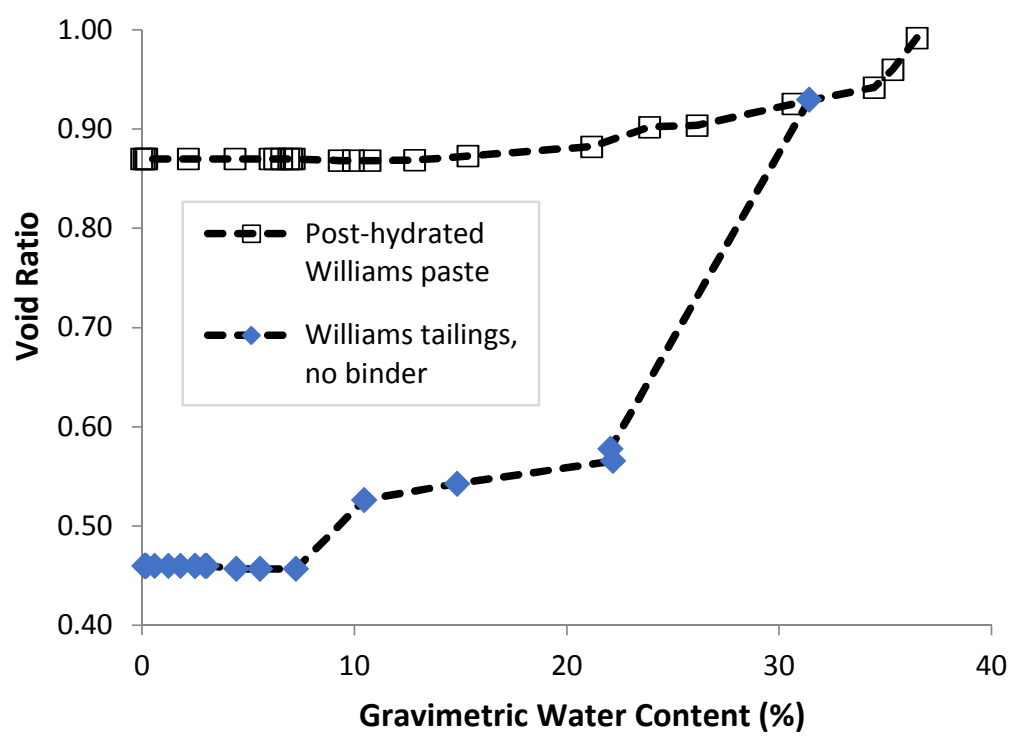

Figure 5. 


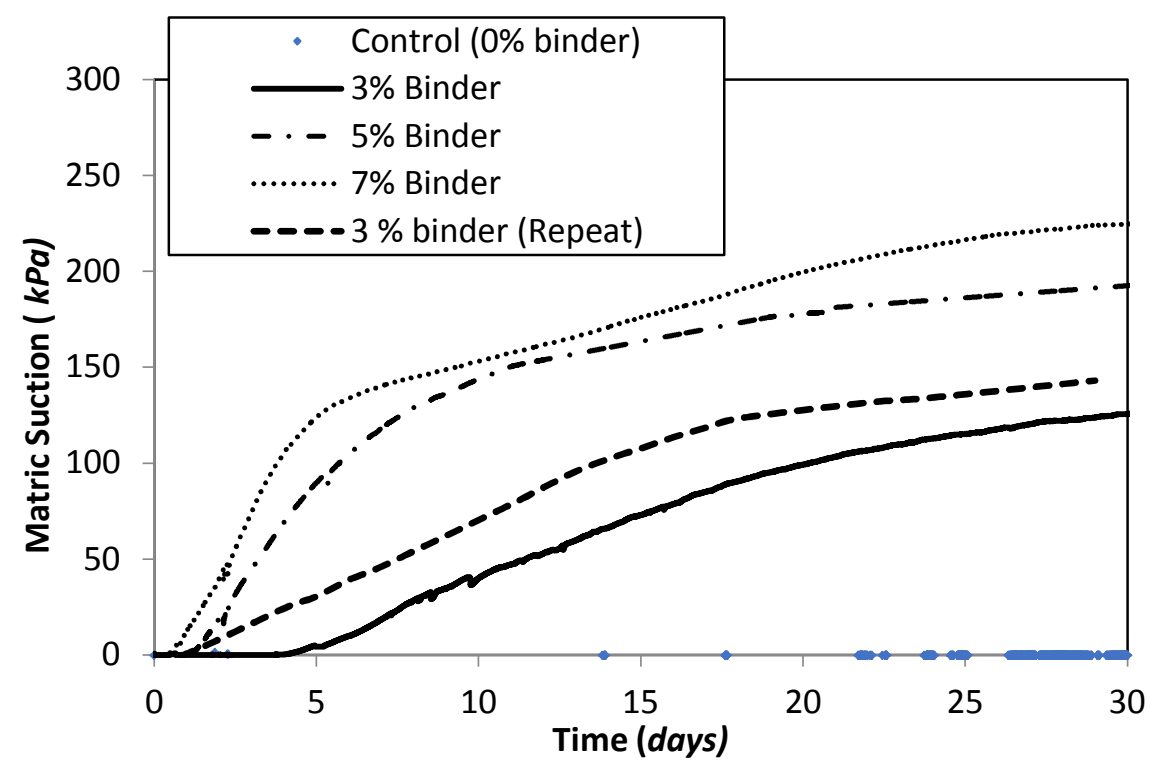

Figure 6. 


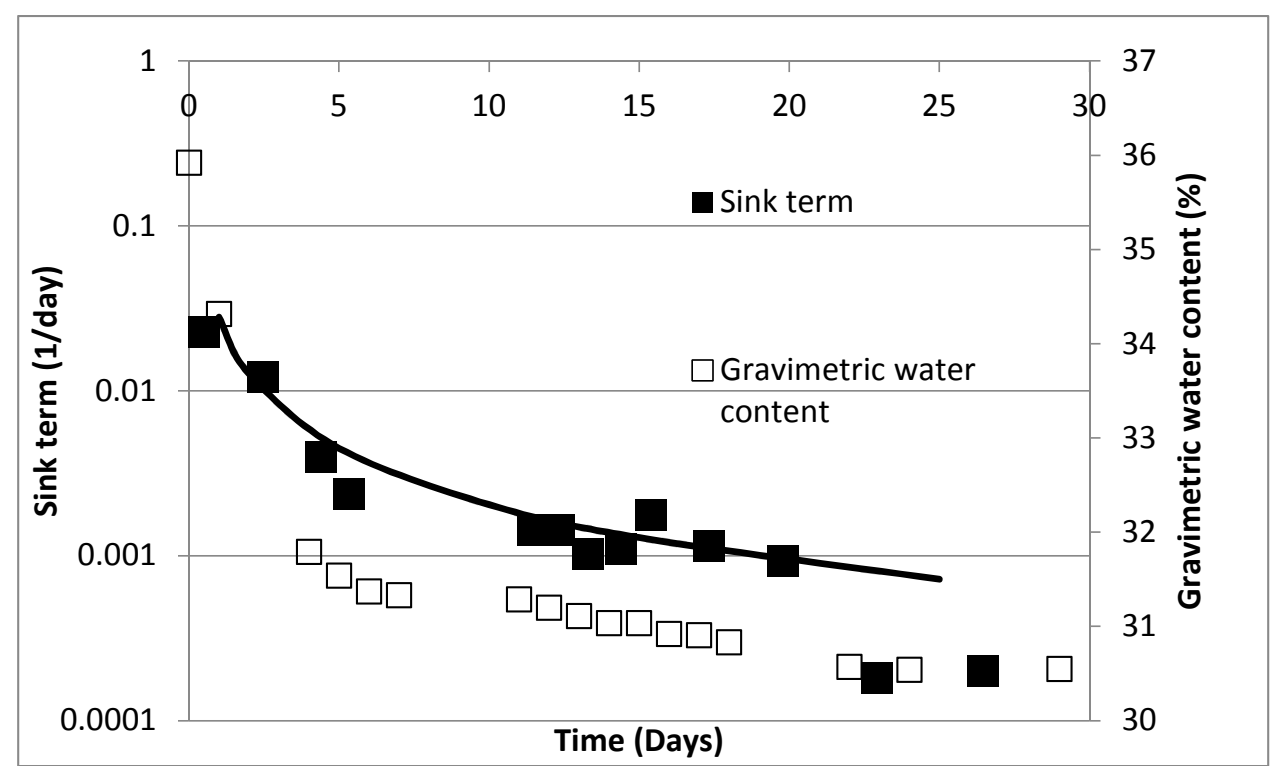

Figure 7. 


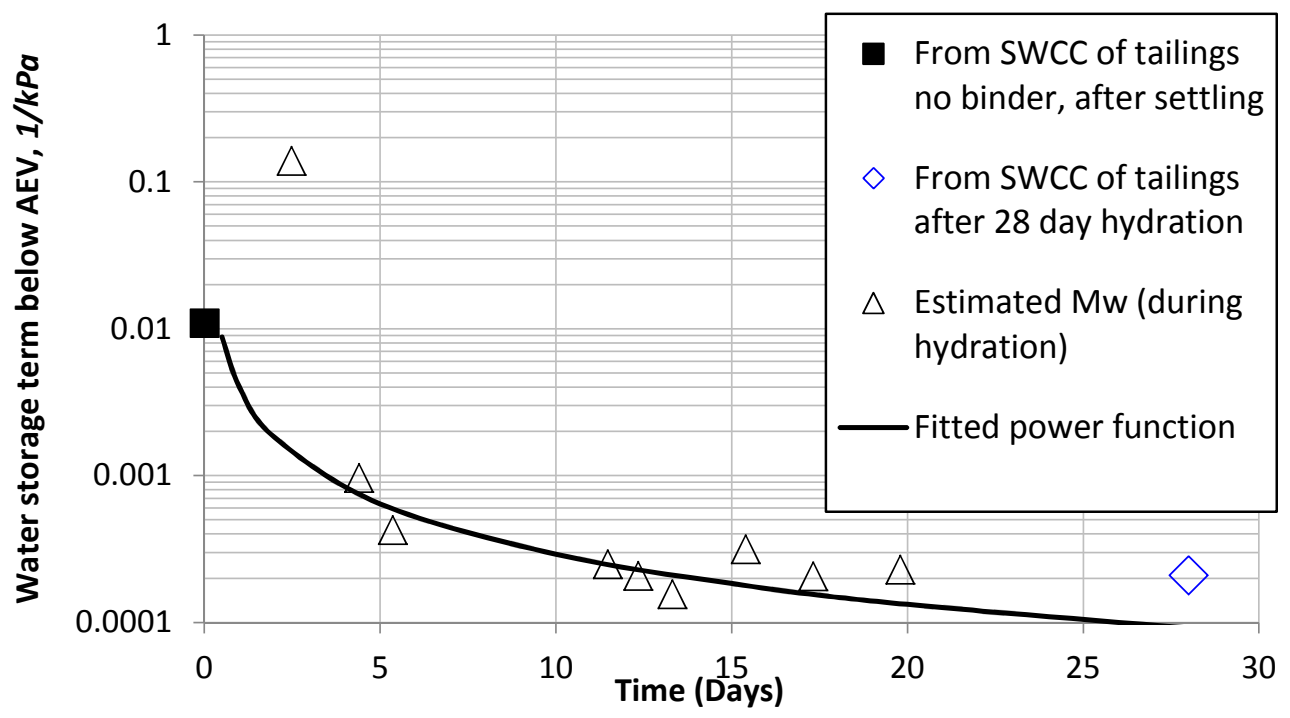

Figure 8. 


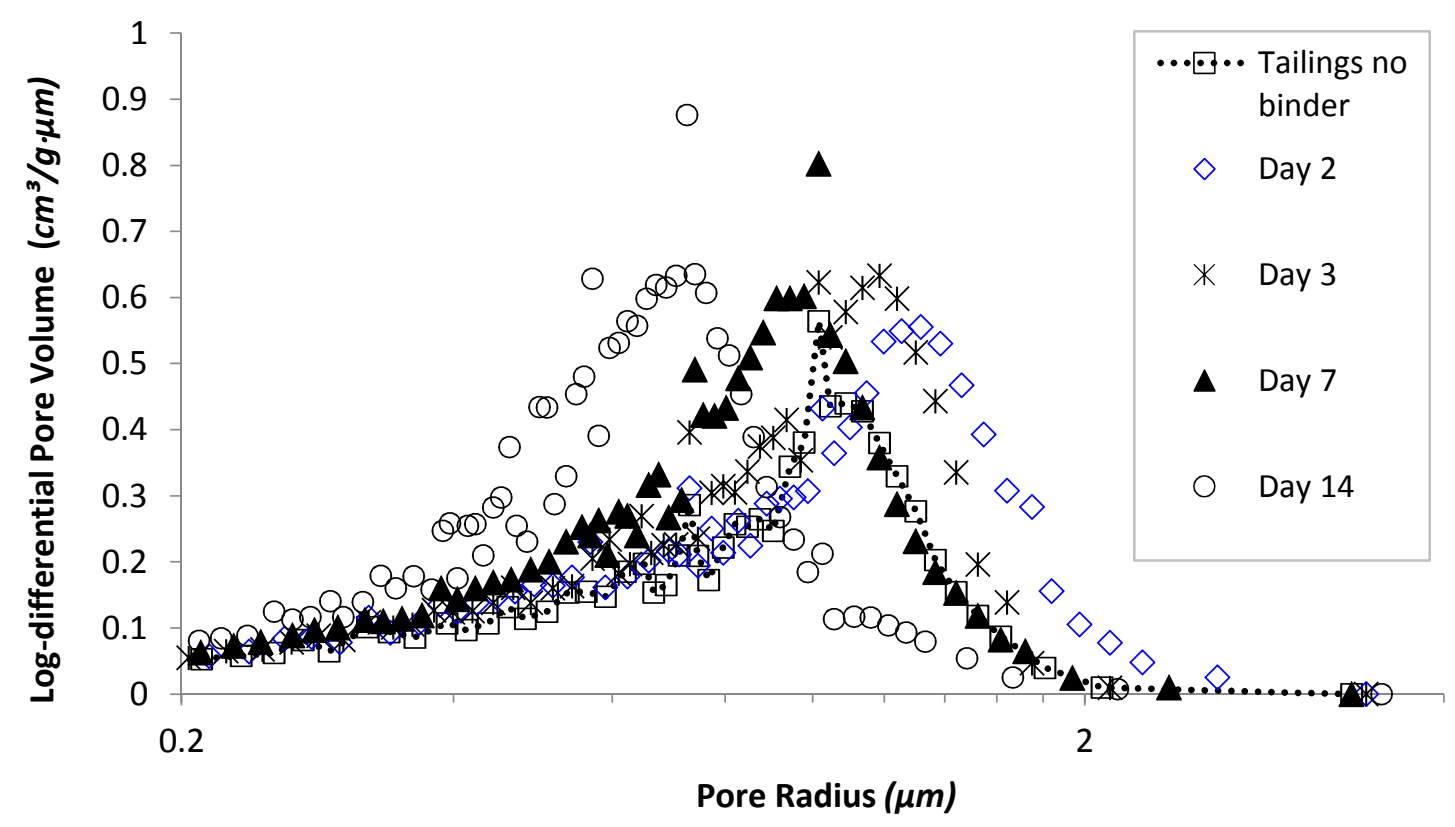

(a)

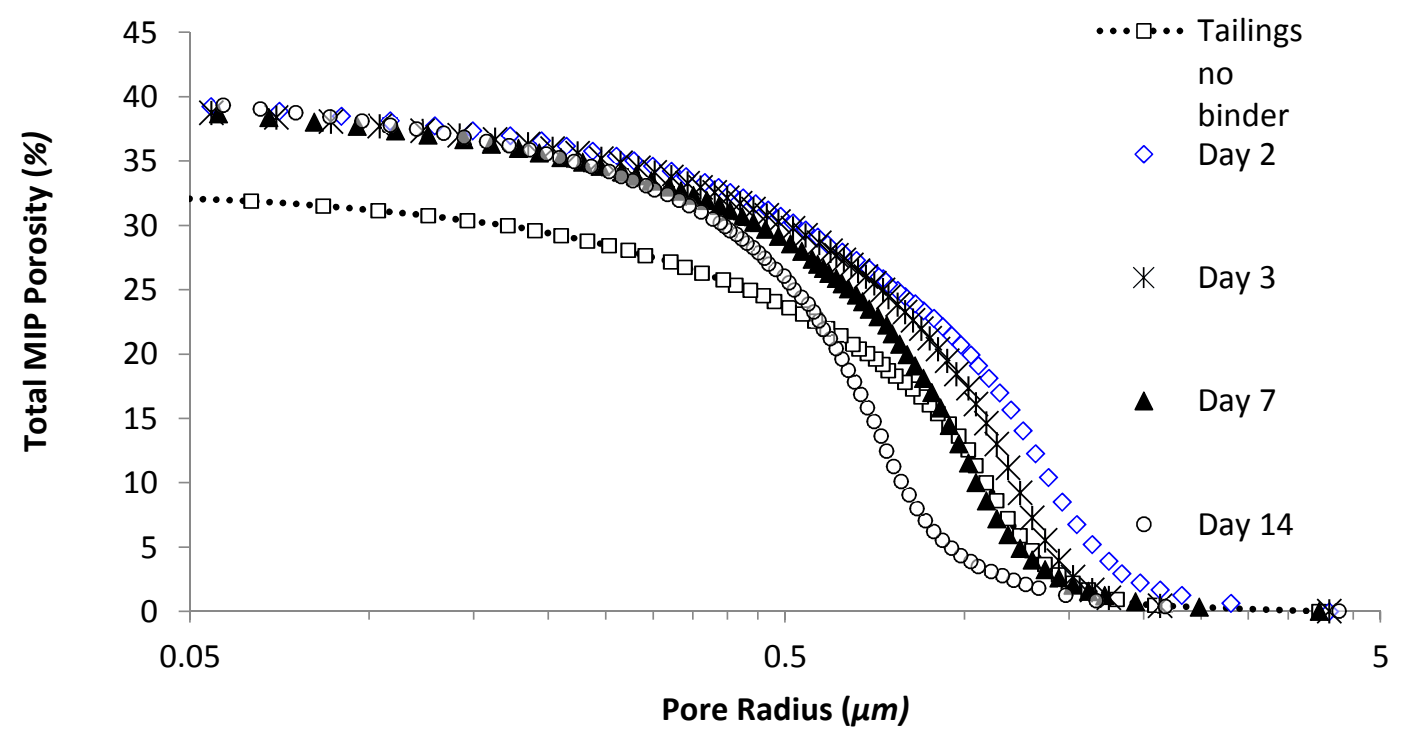

(b)

Figure 9. 


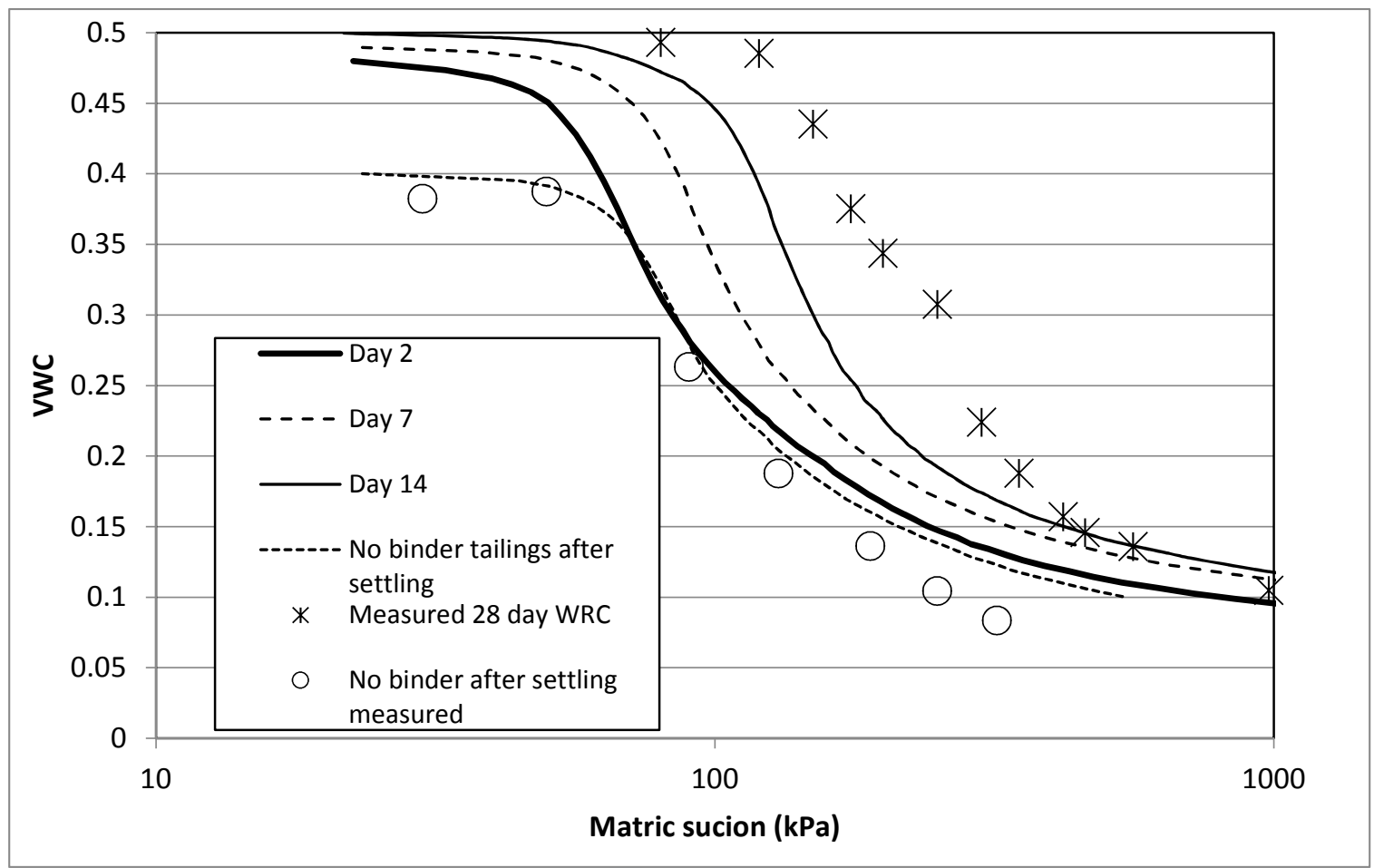

Figure 10. 


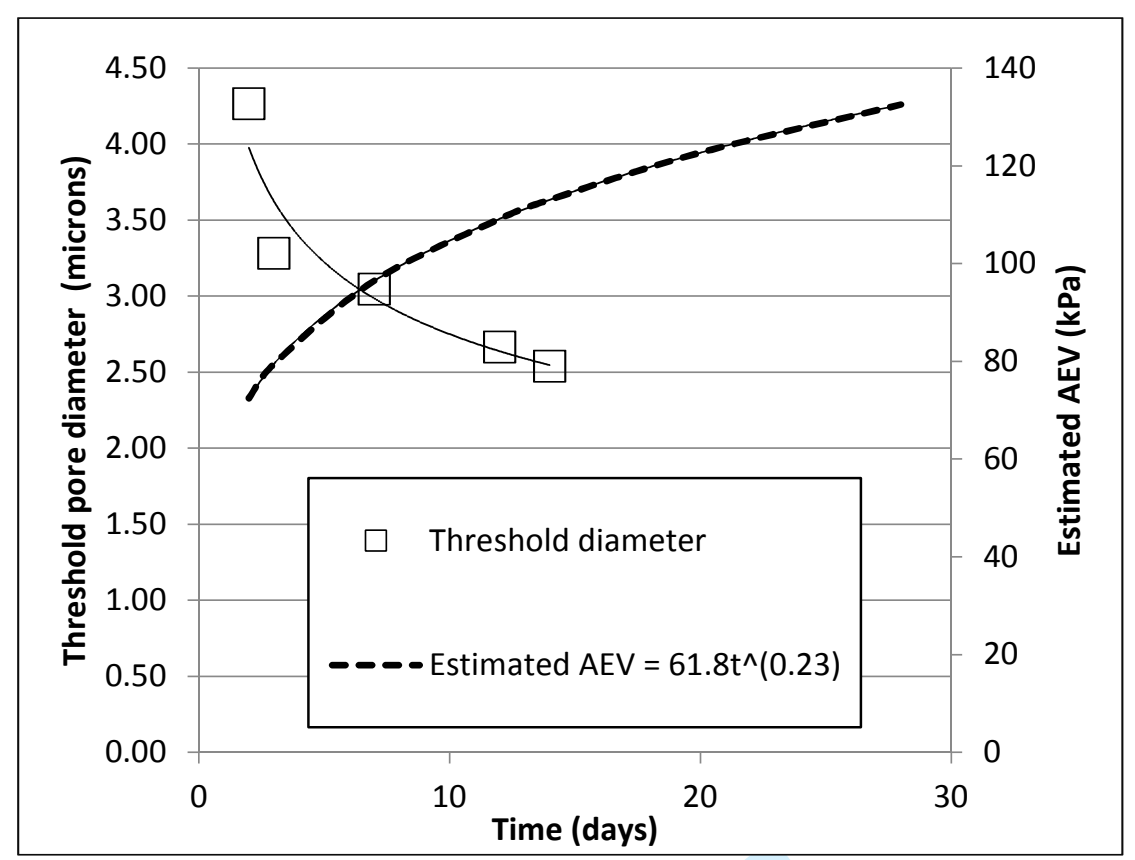

Figure 11. 


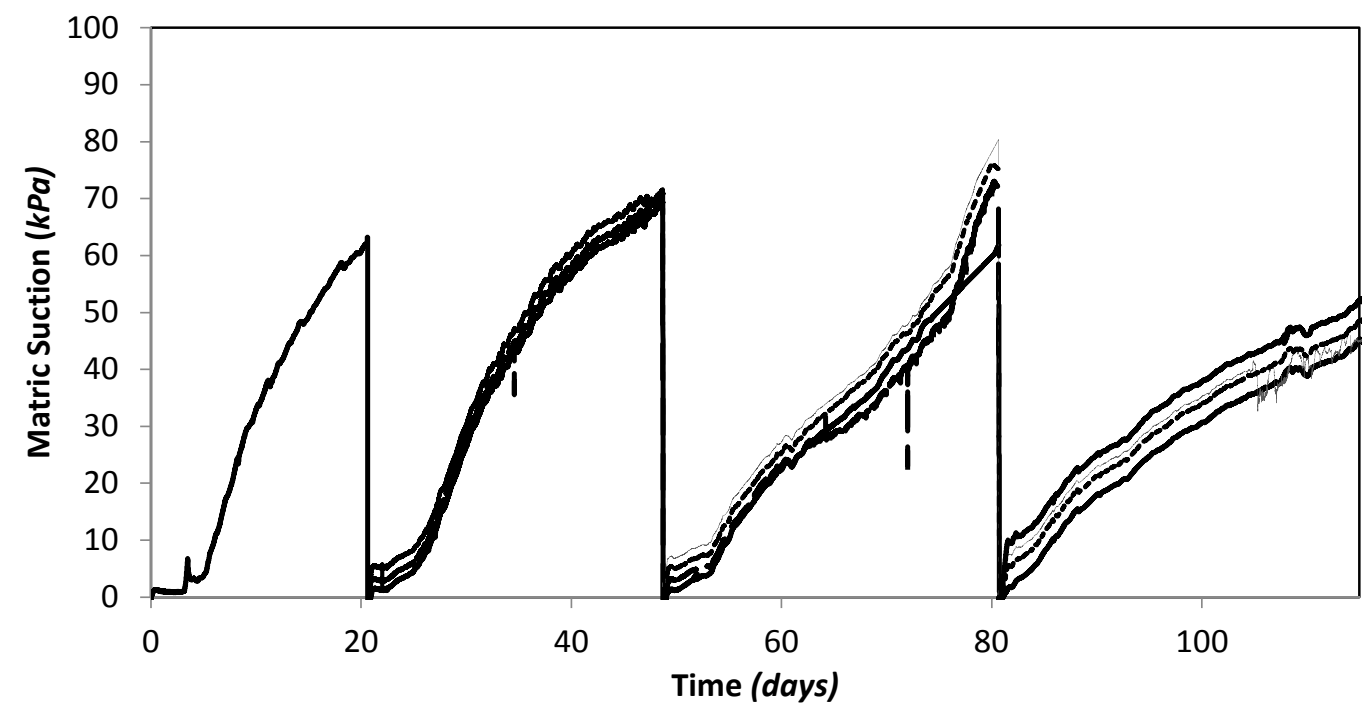

Figure 12. 


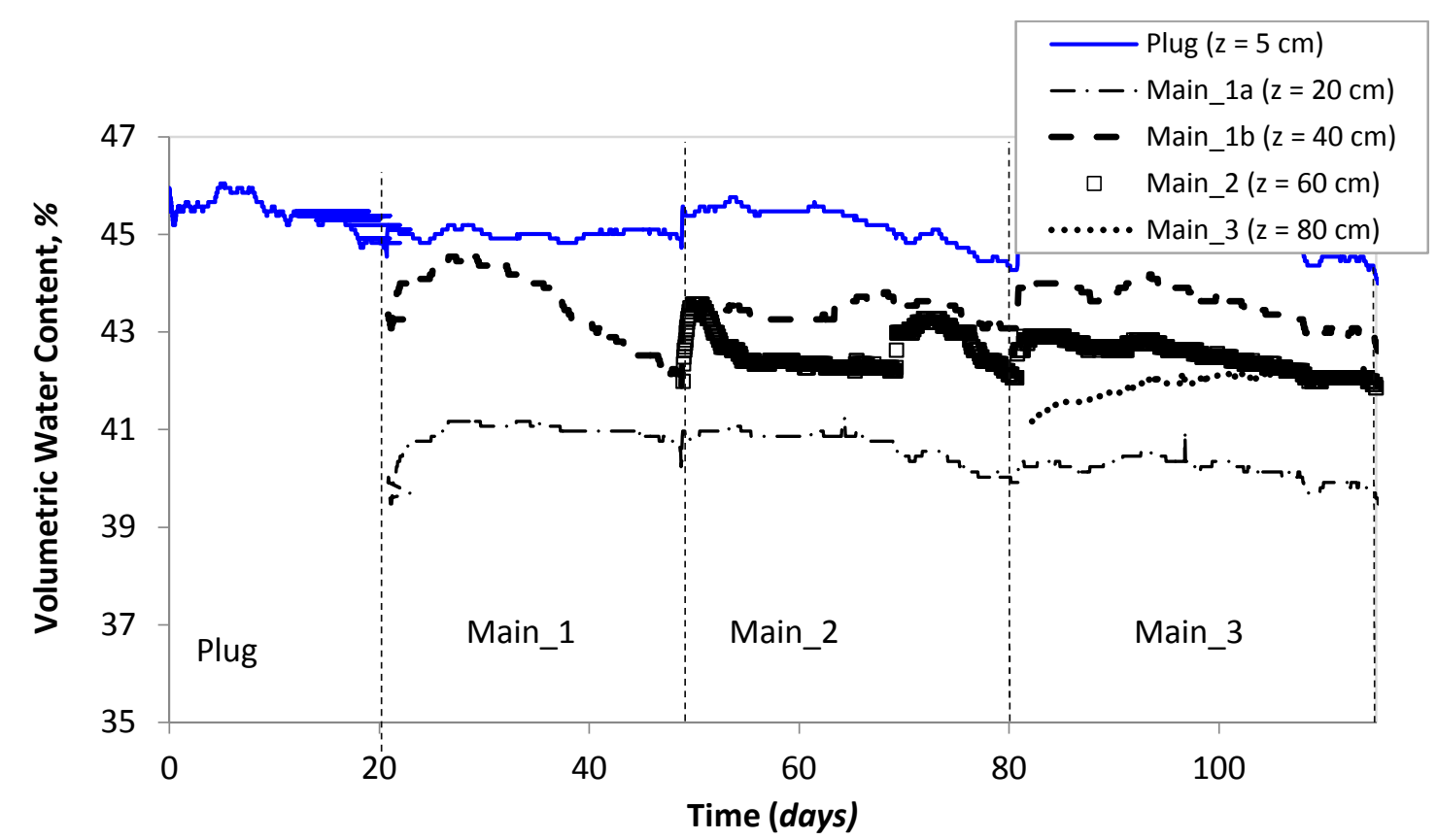

Figure 13. 


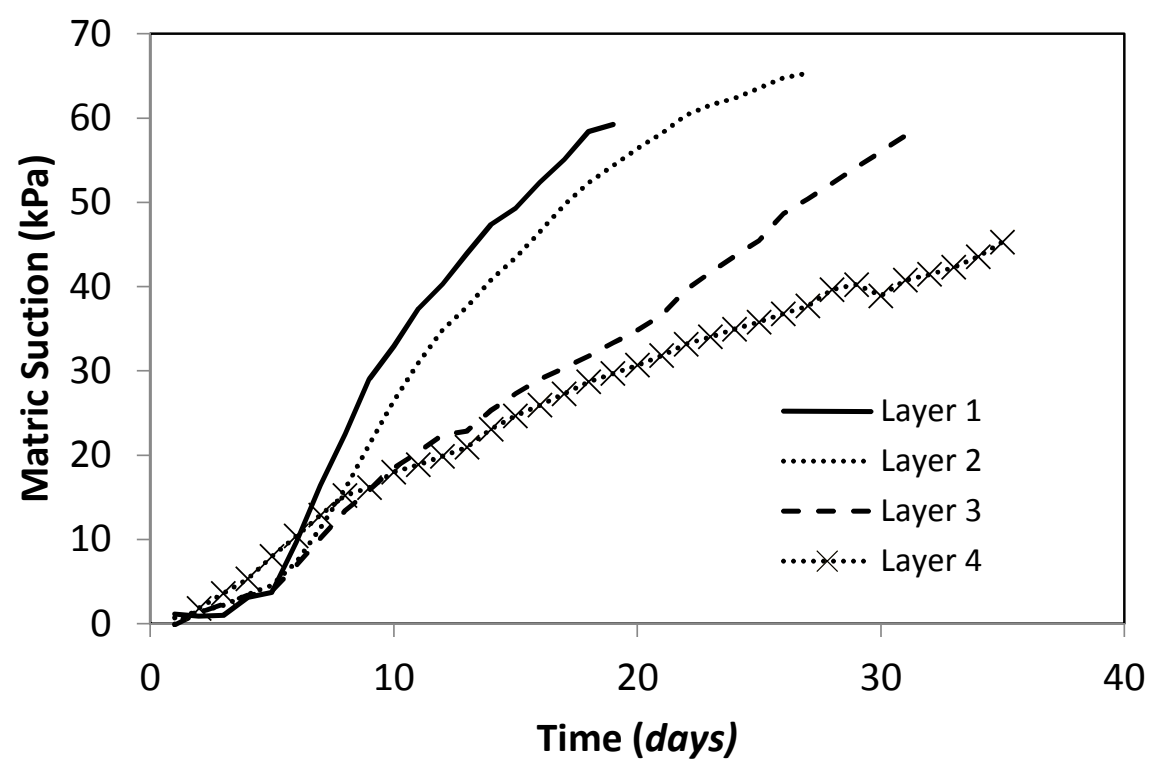

Figure 14. 


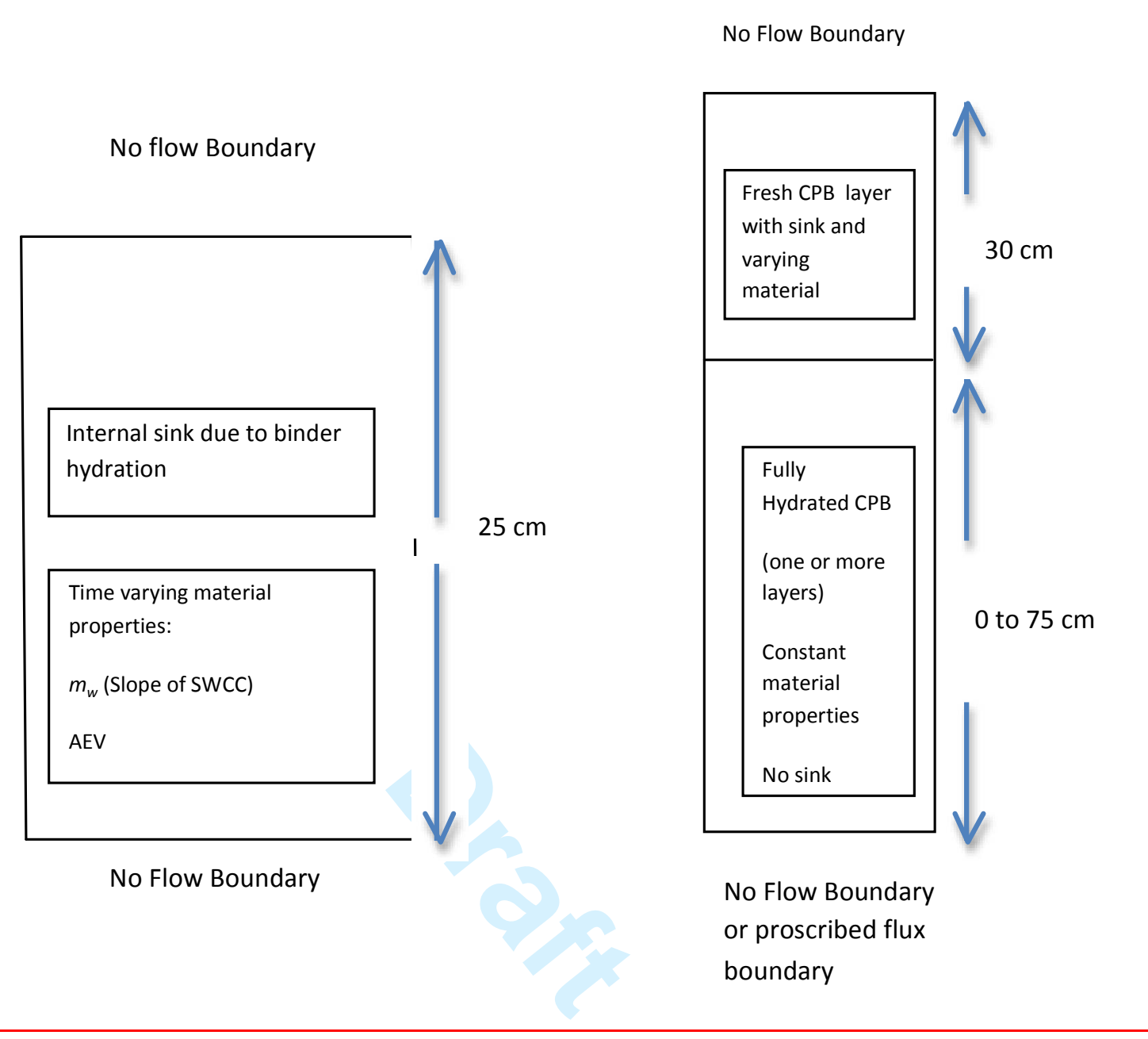

Figure 15. 


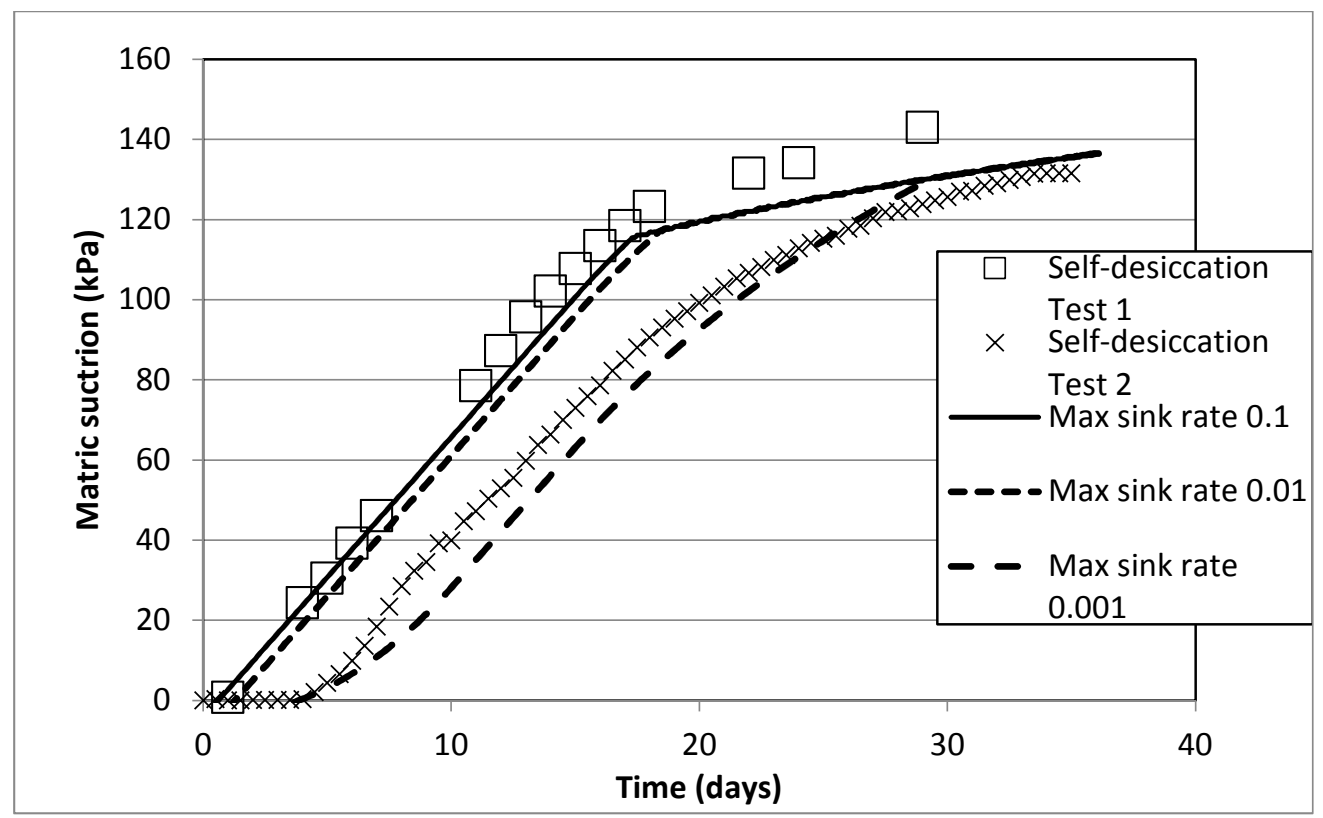

Figure 16. 


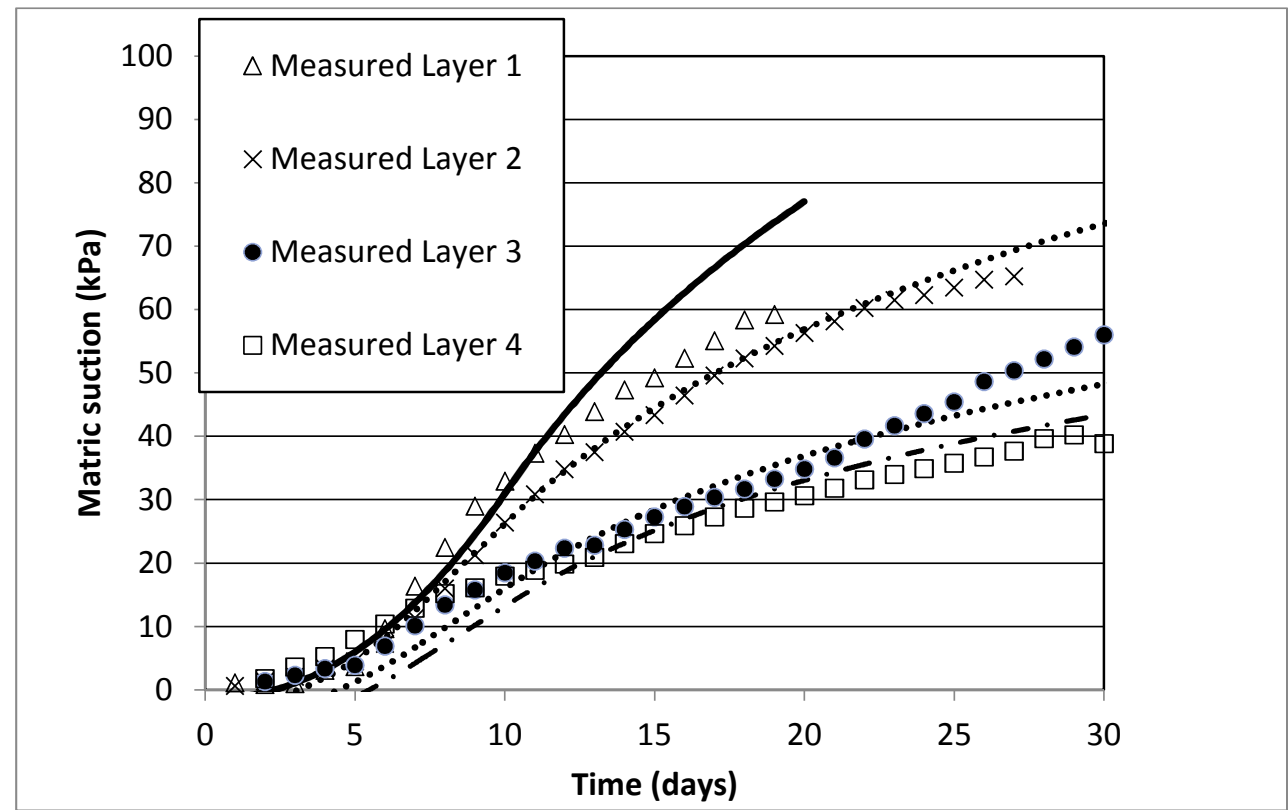

Figure 17. 


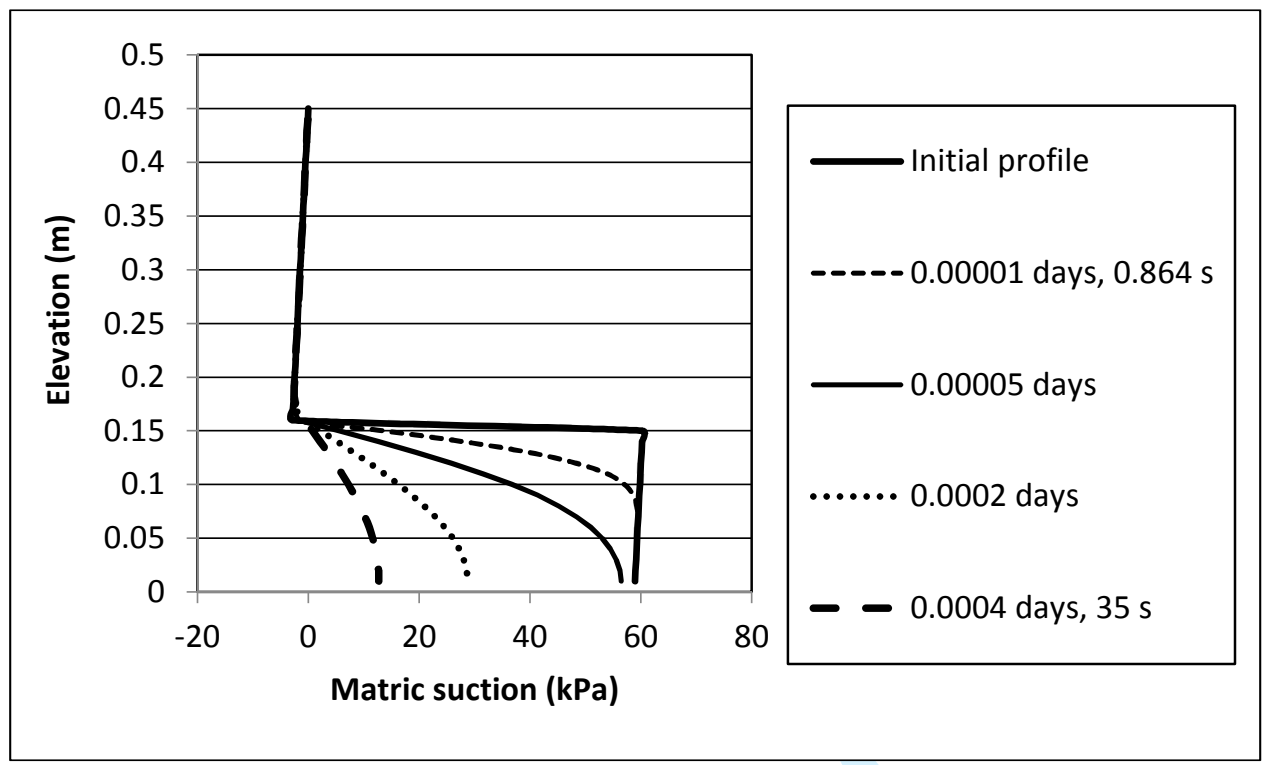

Figure 18. 